\title{
Compatibility of iridium thin films with the silicon pore optics technology for Athena
}

\author{
Svendsen, S.; Ferreira, D. D.M.; Massahi, S.; Henriksen, P. L.; Gellert, N. C.; S'jegers, A.; Christensen, F. \\ E.; Landgraf, B.; Thete, A.; Collon, M.
}

Total number of authors:

13

Published in:

Proceedings of SPIE

Link to article, DOI:

$10.1117 / 12.2594467$

Publication date:

2021

Document Version

Publisher's PDF, also known as Version of record

Link back to DTU Orbit

Citation (APA):

Svendsen, S., Ferreira, D. D. M., Massahi, S., Henriksen, P. L., Gellert, N. C., S'jegers, A., Christensen, F. E., Landgraf, B., Thete, A., Collon, M., Ferreira, I., Shortt, B., \& Bavdaz, M. (2021). Compatibility of iridium thin films with the silicon pore optics technology for Athena. In S. L. O'Dell, J. A. Gaskin, \& G. Pareschi (Eds.),

Proceedings of SPIE: Optics for EUV, X-Ray, and Gamma-Ray Astronomy X [118220C] SPIE - International Society for Optical Engineering. Proceedings of SPIE - The International Society for Optical Engineering Vol. 11822 https://doi.org/10.1117/12.2594467

\section{General rights}

Copyright and moral rights for the publications made accessible in the public portal are retained by the authors and/or other copyright owners and it is a condition of accessing publications that users recognise and abide by the legal requirements associated with these rights.

- Users may download and print one copy of any publication from the public portal for the purpose of private study or research.

- You may not further distribute the material or use it for any profit-making activity or commercial gain

- You may freely distribute the URL identifying the publication in the public portal 


\title{
Compatibility of iridium thin films with the Silicon Pore Optics technology for Athena
}

\author{
S. Svendsen ${ }^{a}{ }^{*}$, D. D. M. Ferreira ${ }^{a}$, S. Massahi ${ }^{\text {, }}$ P. L. Henriksen ${ }^{\text {a }}$, N. C. Gellert ${ }^{\mathrm{a}}$, A. 'S Jegers ${ }^{\mathrm{a}}$, \\ F. E. Christensen ${ }^{\mathrm{a}}$, B. Landgraf ${ }^{\mathrm{b}}$, A. Thete $^{\mathrm{b}}$, M. Collon ${ }^{\mathrm{b}}$, I. Ferreira ${ }^{\mathrm{c}}$, B. Shortt ${ }^{\mathrm{c}}$, and M. \\ Bavdaz $^{\mathrm{C}}$ \\ a DTU Space, Technical University of Denmark, Elektrovej 327, 2800 Kgs. Lyngby, Denmark \\ ${ }^{\mathrm{b}}$ cosine, Oosteinde 36, 2361 HE Warmond, Netherlands \\ ${ }^{c}$ European Space Agency (ESTEC), Keplerlaan 1, PO Box 299, 2200 AG Noordwijk, Netherlands
}

\begin{abstract}
The development of high-quality thin film coatings for the Athena X-ray optics is progressing, following the commissioning of an industrial scale coating facility. The assembly of silicon pore optics into mirror modules for the Athena telescope requires wet-chemical exposure of coated mirror plates to prepare bonding areas for stacking, as well as an annealing step to improve bond strength. It is therefore critical to evaluate how these post-coating processes could affect the mirror coating performance and stability.

We present X-ray reflectometry characterization of iridium thin films deposited on photoresist patterned Silicon Pore Optics plates to investigate the compatibility with the stacking process steps for the manufacturing of the Athena optics.
\end{abstract}

Keywords: Athena, X-ray optics, Silicon Pore Optics, thin film, iridium

\section{INTRODUCTION}

The Athena (Advanced Telescope for High Energy Astrophysics) observatory is a selected L-class mission under preparation by the European Space Agency (ESA) ${ }^{1}$. The telescope will feature X-ray optics based on the Silicon Pore Optics (SPO) technology with individual mirror plates coated with X-ray reflective thin films.

As the optics development is scaling up for the industrialized mirror plate production and assembly ${ }^{2-4}$, the development of X-ray mirror coatings for Athena is progressing alongside, ${ }^{5-14}$ with several aspects of material stability ${ }^{14-16}$ and optimization of performance ${ }^{17}$ being investigated.

The thin film designs under study for the Athena X-ray mirrors at present include iridium single-layers, and bilayers of iridium with a low-Z overcoat of either boron carbide, silicon carbide, or carbon.

One of the critical aspects in adopting a coating design is addressing the compatibility of the candidate materials with the wet-chemical, mechanical and thermal post-processing required for the SPO technology.

Previous studies based on preliminary wet-chemical treatment have indicated compatibility of iridium thin films ${ }^{14,18}$. Since then, further refinement of the wet-chemical processes has been enabled with the installation of a fully automated wet bench at cosine Research BV ${ }^{19}$.

In this paper, we present X-ray reflectometry (XRR) characterization of coated, photoresist patterned SPO mirror plates to evaluate the compatibility of iridium thin films with the most representative post-coating processes of the SPO technology.

\footnotetext{
*sasv@space.dtu.dk
} 


\section{SAMPLE PREPARATION}

The iridium thin films were produced by DC magnetron sputtering in the Von Ardenne BS1500S coating machine installed at cosine Research BV $\mathrm{BV}^{20,21}$.

The iridium thin films were deposited onto photoresist patterned SPO plates, representative of the Athena middle-radius mirror plates. The plates were exposed to in-situ plasma cleaning prior to thin film deposition in order to remove surface contamination, ensuring a smooth surface and compatibility with the wet-chemical cleaning procedure ${ }^{14,22}$.

For coating, the argon sputtering pressure was $3.4 \cdot 10^{3}$ mbar, and a magnetron power of $1800 \mathrm{~W}$ was applied. The iridium thin films were coated with a thickness of $\sim 20 \mathrm{~nm}$. While the optimized iridium-only design for Athena assumes a thickness of $10 \mathrm{~nm}^{10}$, these thin films are still representative for characterization of the overall material compatibility with the SPO processing steps.

\subsection{Post-coating processing}

Figure 1 presents the processing steps at plate and stack level. In this study, the impact of the latter three post-coating treatments, described below, is investigated in terms of thin films quality and stability.

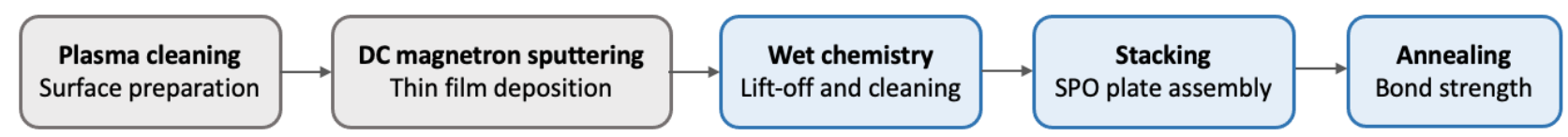

Figure 1: Overview of the processing steps from uncoated SPO plate to X-ray mirror stacks. The reflector surfaces are prepared by plasma cleaning prior to coating. After thin film deposition, the coated SPO plates undergo wet chemistry, stacking, and annealing.

The SPO technology utilizes two wet-chemical processes of coated mirror plates to prepare the surfaces for stacking: Lift-off and cleaning. Photoresist lift-off is performed using a DMSO bath to remove the parallel stripes of the thin film, exposing the silicon bonding areas. A diluted Standard Clean 1 (SC-1) is used to remove organic material and activate the bonding surfaces. Both wet-chemical steps were carried out in the new wet bench at cosine Research BV.

After wet-chemical treatment, SPO plates are precisely stacked using a robotic system. The post-stacking annealing is used to increase the bond strength between adjacent plates in the stack. The evaluation of effects of annealing representative of the stacking procedure was carried out using a LabCompanion OV-11 vacuum oven at DTU Space. The stack was heated to $200{ }^{\circ} \mathrm{C}$ for 50 hours in air, including 2 hours of pre-heating.
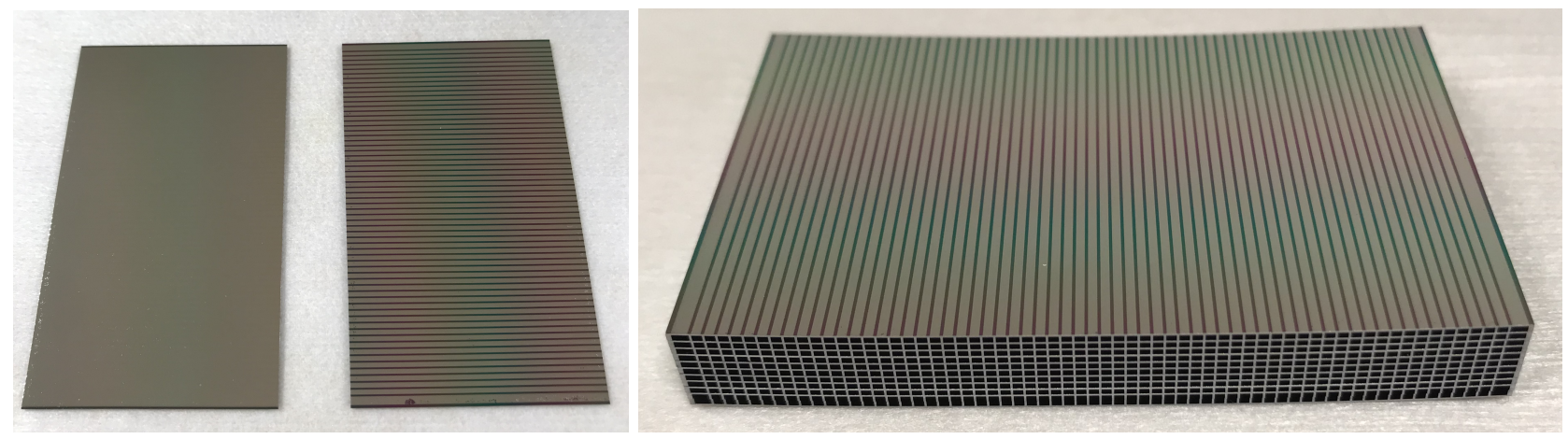

Figure 2: The iridium coated samples. From left to right: SPO plate 01219-12 (no post-coating treatment), SPO plate 01219-09 (lift-off and cleaning), and SPO stack HPO-1722 (before annealing).

\section{CHARACTERIZATION AND MODELING}

The potential effects of thin film post-processing required for the SPO technology were evaluated through XRR characterization of iridium coated middle-radius SPO plates without any post-coating treatment (ID 01912-12) 
and after lift-off and cleaning (ID 01912-09). A 10-plate middle-radius SPO stack (HPO-1722) was characterized before and after annealing.

XRR measurements were carried out at DTU Space using the $8.048 \mathrm{keV}$ reflectometer and the LEXR system operating at $1.487 \mathrm{keV} .{ }^{23}$ The angular resolution for both systems is assumed to be $7 \mathrm{mdeg}$. For the $8.048 \mathrm{keV}$ measurements, the samples were illuminated with a $0.4 \times 0.12 \mathrm{~mm}^{2}$ beam size, while $1.487 \mathrm{keV}$ measurements were performed with a $0.5 \times 0.4 \mathrm{~mm}^{2}$ beam. The error bars indicate statistical uncertainties only.

The SPO plates were measured at the center position. For the stack, the top plate was measured in three spots: $\mathrm{x} 0$ (center), $\mathrm{xm} 2$ (2 $\mathrm{mm}$ above center), xp2 (2 mm below center). The top plate was assumed to be representative of the reflective surfaces throughout the stack.

The XRR measurements were fitted in $\mathrm{IMD}^{24}$ using a model with a silicon dioxide substrate and an iridium thin film layer. The material densities were assumed as the nominal values tabulated for the CXRO/LLNL determination of optical constants, as previous studies suggest that the iridium is deposited with the same density within $<0.1 \%^{13}$.

For the $1.487 \mathrm{keV}$ data, a hydrocarbon overlayer, modeled as a simple $\mathrm{COH}$ compound with a fixed density of $1.00 \mathrm{~g} / \mathrm{cm}^{3}$, was included to account for a surface contamination layer.

\subsection{Results}

Figures 3-6 present XRR measurements of the iridium coated mirror plates along with the best fits. The best fits parameters are given in Table 1.
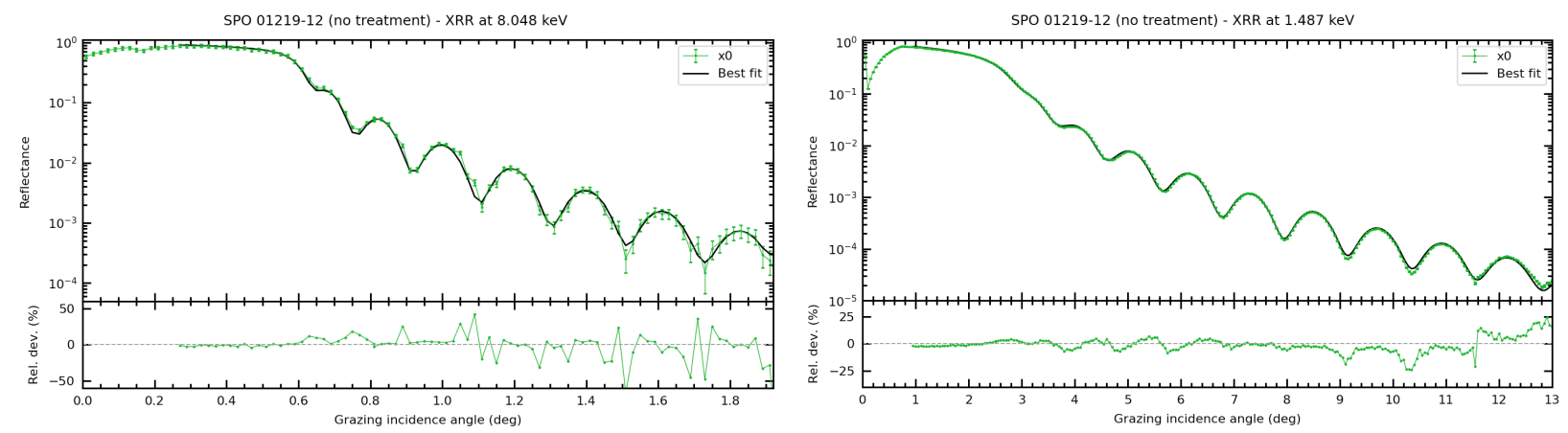

Figure 3: XRR measurements at $8.048 \mathrm{keV}$ and $1.487 \mathrm{keV}$ with best fits for iridium coated SPO plate 01219-12 (no post-coating treatment).
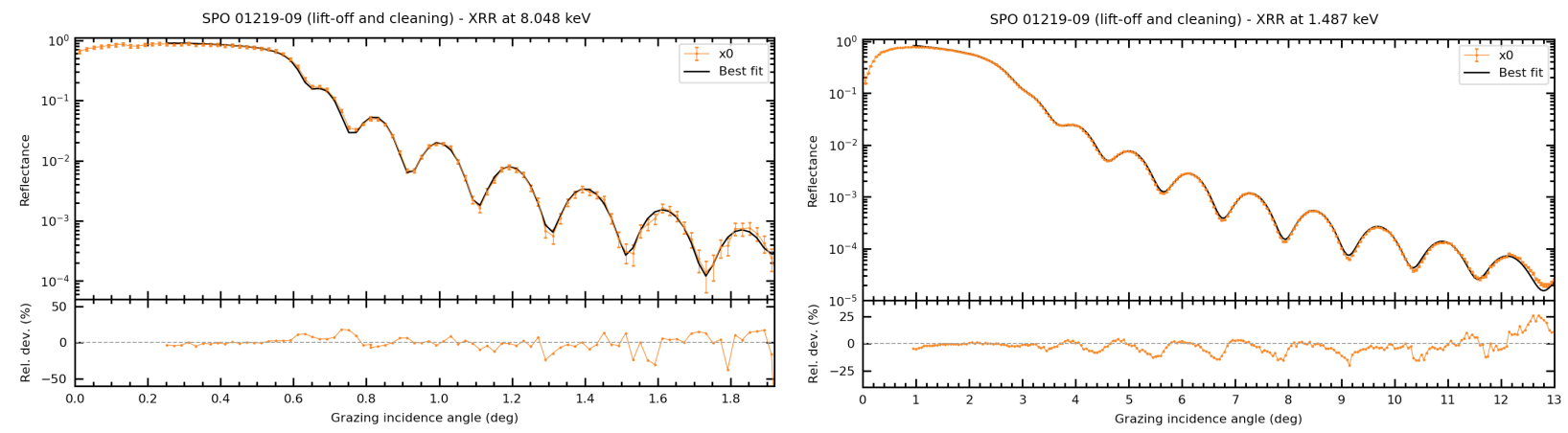

Figure 4: XRR measurements at $8.048 \mathrm{keV}$ and $1.487 \mathrm{keV}$ with best fits for iridium coated SPO plate 01219-09 (after wet-chemical lift-off and cleaning). 

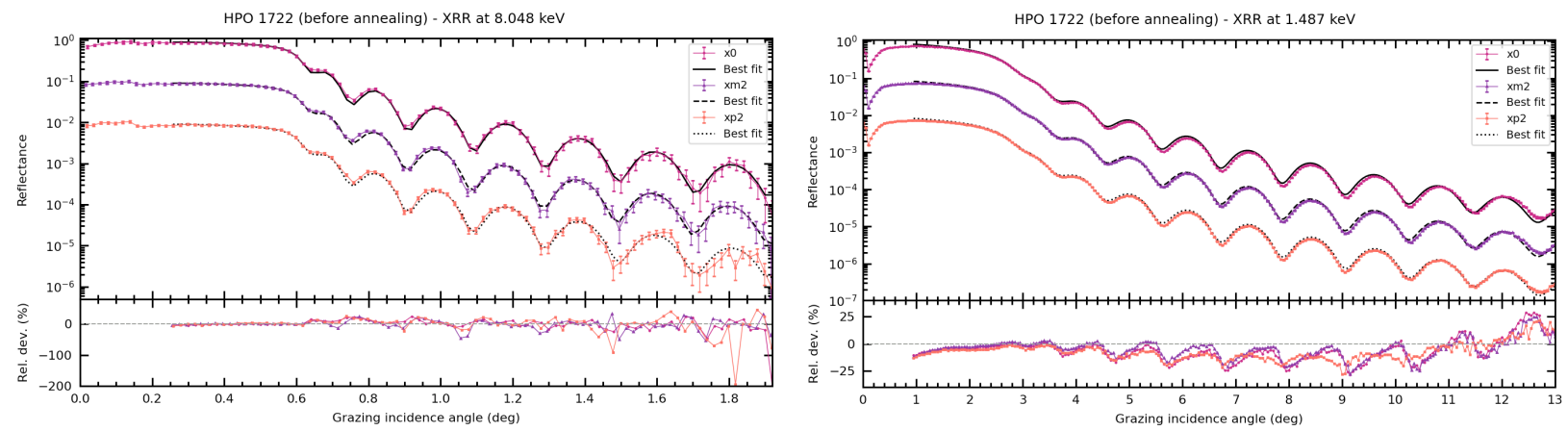

Figure 5: XRR measurements at $8.048 \mathrm{keV}$ and $1.487 \mathrm{keV}$ with best fits for iridium coated stack HPO-1722 (before annealing). The three measured spots are offset by $10^{-1}$ and $10^{-2}$ in reflectance for visibility.
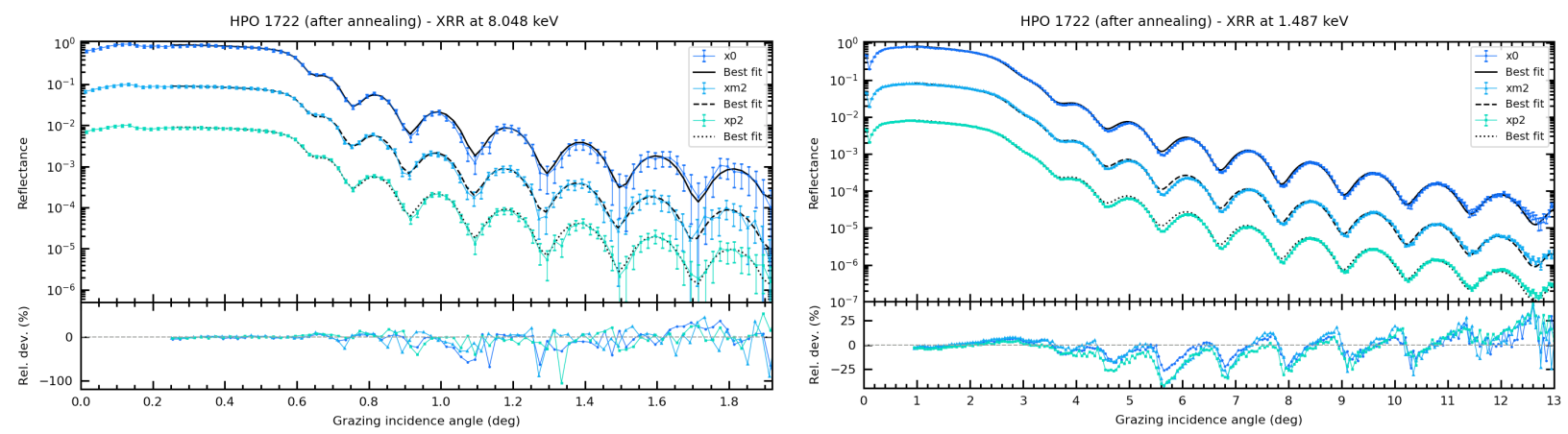

Figure 6: XRR measurements at $8.048 \mathrm{keV}$ and $1.487 \mathrm{keV}$ with best fits for iridium coated stack HPO-1722 (after annealing). The three measured spots are offset by $10^{-1}$ and $10^{-2}$ in reflectance for visibility.

Table 1: Fit parameters to XRR measurements performed at $1.487 \mathrm{keV}$ and $8.048 \mathrm{keV}$ of the iridium coated SPO plates and stack. Parameters marked with ${ }^{\dagger}$ were coupled during fitting.

\begin{tabular}{|c|c|c|c|c|c|c|c|c|}
\hline \multirow{2}{*}{ ID } & \multirow{2}{*}{ Treatment } & \multirow{2}{*}{ Data } & \multirow{2}{*}{ Position } & \multicolumn{2}{|c|}{ Hydrocarbons } & \multicolumn{2}{|c|}{ Iridium } & \multirow{2}{*}{$\begin{array}{r}\text { Substrate } \\
\sigma(\mathrm{nm})\end{array}$} \\
\hline & & & & $\mathrm{z}(\mathrm{nm})$ & $\sigma(\mathrm{nm})$ & $\mathrm{z}(\mathrm{nm})$ & $\sigma(\mathrm{nm})$ & \\
\hline \multirow{2}{*}{ 01219-12 } & \multirow{2}{*}{ No treatment } & $1.487 \mathrm{keV}$ & $\mathrm{x} 0$ & 1.6 & $0.35^{\dagger}$ & 19.3 & $0.35^{\dagger}$ & 0.51 \\
\hline & & $8.048 \mathrm{keV}$ & $\mathrm{x} 0$ & - & - & 19.1 & 0.33 & 0.53 \\
\hline \multirow{2}{*}{ 01219-09 } & \multirow{2}{*}{ Lift-off, cleaning } & $1.487 \mathrm{keV}$ & $\mathrm{x} 0$ & 1.8 & $0.36^{\dagger}$ & 19.3 & $0.36^{\dagger}$ & 0.49 \\
\hline & & $8.048 \mathrm{keV}$ & $\mathrm{x} 0$ & - & - & 19.0 & 0.38 & 0.47 \\
\hline \multirow{6}{*}{ HPO- 1722} & \multirow{6}{*}{$\begin{array}{l}\text { Before annealing } \\
\text { (Lift-off, cleaning, } \\
\text { stacking) }\end{array}$} & \multirow{3}{*}{$1.487 \mathrm{keV}$} & $\mathrm{x} 0$ & 1.9 & $0.39^{\dagger}$ & 19.5 & $0.39^{\dagger}$ & 0.52 \\
\hline & & & $\mathrm{xm} 2$ & 1.8 & $0.37^{\dagger}$ & 19.5 & $0.37^{\dagger}$ & 0.50 \\
\hline & & & $\mathrm{xp} 2$ & 1.8 & $0.38^{\dagger}$ & 19.5 & $0.38^{\dagger}$ & 0.52 \\
\hline & & \multirow{3}{*}{$8.048 \mathrm{keV}$} & $\mathrm{x} 0$ & - & - & 19.3 & 0.31 & 0.47 \\
\hline & & & $\mathrm{xm} 2$ & - & - & 19.4 & 0.33 & 0.46 \\
\hline & & & $\mathrm{xp} 2$ & - & - & 19.3 & 0.32 & 0.49 \\
\hline \multirow{6}{*}{ HPO-1722 } & \multirow{6}{*}{$\begin{array}{c}\text { After annealing } \\
\text { (Lift-off, cleaning, } \\
\text { stacking, annealing) }\end{array}$} & \multirow{3}{*}{$1.487 \mathrm{keV}$} & $\mathrm{x} 0$ & 2.1 & $0.38^{\dagger}$ & 19.5 & $0.38^{\dagger}$ & 0.47 \\
\hline & & & $\mathrm{xm} 2$ & 2.1 & $0.42^{\dagger}$ & 19.5 & $0.42^{\dagger}$ & 0.50 \\
\hline & & & $\mathrm{xp} 2$ & 2.1 & $0.40^{\dagger}$ & 19.5 & $0.40^{\dagger}$ & 0.49 \\
\hline & & \multirow{3}{*}{$8.048 \mathrm{keV}$} & $\mathrm{x} 0$ & - & - & 19.3 & 0.35 & 0.44 \\
\hline & & & $\mathrm{xm} 2$ & - & - & 19.3 & 0.34 & 0.40 \\
\hline & & & $\mathrm{xp} 2$ & - & - & 19.4 & 0.35 & 0.45 \\
\hline
\end{tabular}


The best fit parameters give no indication that the iridium-only thin film is affected by the SPO post-coating process steps. The minor iridium thickness variation is attributed to coating non-uniformity of a few percent.

Figure 7 shows the measured central spots on the SPO plates and the top plate of the stack to compare the XRR performances at $8.048 \mathrm{keV}$ and $1.487 \mathrm{keV}$. Within the measurement reproducibility, these results support the observation that iridium thin films are not affected by the wet-chemical treatment, mechanical stacking, and annealing.
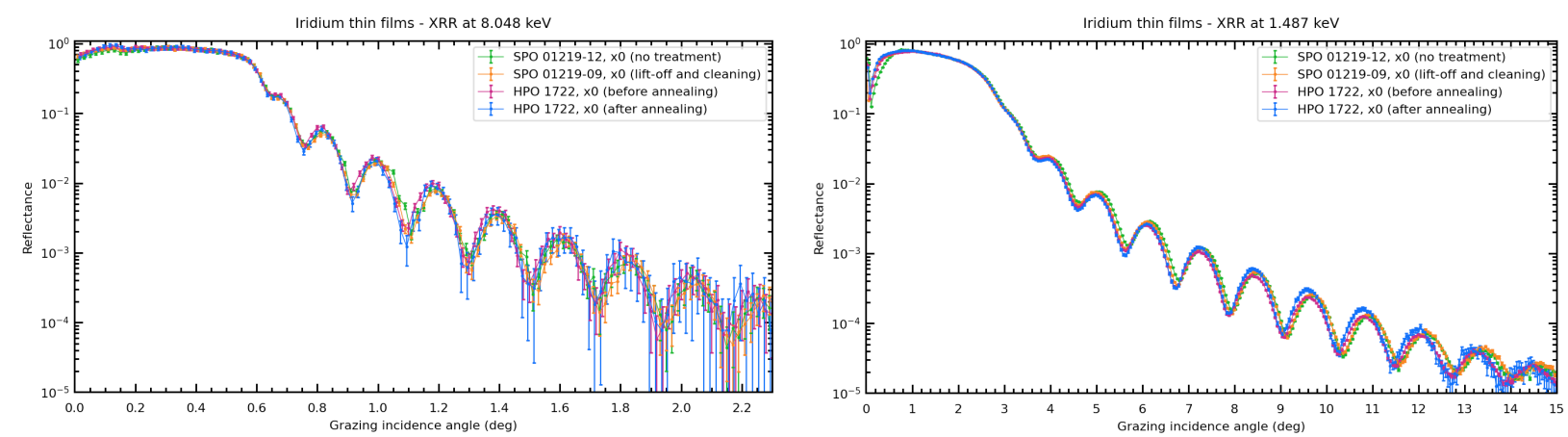

Figure 7: XRR measurements at $8.048 \mathrm{keV}$ and $1.487 \mathrm{keV}$ of the iridium coated plates after each step in the post-coating sequence.

\section{SUMMARY}

Thin films of iridium coated on photoresist patterned SPO plates were presented to evaluate the impact of the most representative post-coating treatments required for the industrialized production of SPO mirrors for the Athena telescope. Based on the presented XRR measurements of the iridium-only coating, compatibility with the SPO production processes was demonstrated.

The measured XRR performance at $8.048 \mathrm{keV}$ and $1.487 \mathrm{keV}$ of the coated mirrors and the derived best fit parameters give no indication of change in thickness, roughness or density of the iridium single-layer thin films. The $\sim 2 \%$ iridium thickness variation observed across the presented samples is expected from the margin of coating uniformity for the coating machine.

XRR measurements of the SPO stack were carried out on the reflective surface of the top plate only, assuming this to be representative of the overall performance of the coated stack. However, since a temperature gradient through the stack during annealing could have an effect on the coating, in particular for the bilayer designs with a low-Z material, a strategy to best illuminate the pores and measure the thin film performance is being developed.

The results suggest that iridium thin films produced in the Athena-dedicated coating machine are compatible with the entire SPO stacking process. This establishes a baseline for future studies to investigate the stability of performance for the low-Z overcoat candidate materials and to establish their compatibility with the SPO technology.

\section{ACKNOWLEDGEMENT}

This activity was funded by the European Space Agency under contract no. 4000116080/15/NL/BW.

\section{REFERENCES}

[1] Nandra, K., Barret, D., Barcons, X., et al., "The Hot and Energetic Universe: A White Paper presenting the science theme motivating the Athena+ mission," astro-ph.HE arXiv:1306.2307 (2013).

[2] Bavdaz, M., Wille, E., Ferreira, I., et al., "The ATHENA X-ray Optics Development and Accommodation," 11852, SPIE (2020). 
[3] Collon, M., Babic, L., Barrière, N., et al., "X-ray mirror development and production for the Athena telescope," 11852, SPIE (2020).

[4] Collon, M. et al., "Silicon Pore Optics x-ray mirror development for the Athena telescope," Proceedings of SPIE 11822 (2021).

[5] A. C. Jakobsen and D. D. M. Ferreira and F. E. Christensen and B. Shortt and M. Collon, "Preliminary coating design and coating developments for ATHENA," Proceedings of SPIE 8147 (2011).

[6] Ferreira, D. D. M., Christensen, F. E., Jakobsen, A. C., Westergaard, N. J. S., and Shortt, B., "ATHENA coating optimization," Proceedings of SPIE 8443 (2012).

[7] Ferreira, D. D. M., Jakobsen, A. C., Christensen, F. E., et al., "Development and characterization of coatings on Silicon Pore Optics substrates for the ATHENA mission," Proceedings of SPIE 8443 (2012).

[8] Ferreira, D. D. M., Christensen, F. E., Jakobsen, A. C., et al., "Coating optimization for the ATHENA+ mission," Proceedings of SPIE $\mathbf{8 8 6 1}$ (2013).

[9] Massahi, S., Ferreira, D. D. M., Christensen, F. E., et al., "'Development and production of a multilayercoated X-ray reflecting stack for the Athena mission"," Proceedings of SPIE 9905 (2016).

[10] Ferreira, D. D. M., Massahi, S., Christensen, F. E., et al., "Design, development, and performance of X-ray mirror coatings for the ATHENA mission," Proceedings of SPIE 10399 (2017).

[11] Ferreira, D. D. M., Svendsen, S., Massahi, S., et al., "Performance and stability of mirror coatings for the ATHENA mission," Proceedings of SPIE 10699 (2018).

[12] Svendsen, S., Massahi, S., Ferreira, D., et al., "Performance and time stability of Ir/SiC X-ray mirror coatings for ATHENA," Proceedings of SPIE 11119 (2019).

[13] Massahi, S., Christensen, F., Ferreira, D. D. M., et al., "Investigation of boron carbide and iridium thin films, an enabling technology for future x-ray telescopes," Applied Optics (2020).

[14] Svendsen, S., Ferreira, D. D. M., Massahi, S., et al., "Status of the Ir and Ir/SiC coating development for the Athena optics," 11444, SPIE (2020).

[15] Henriksen, P. et al., "Impact of thermal annealing on composition and performance of X-ray mirror coatings for Athena," Proceedings of SPIE 11822 (2021).

[16] Massahi, S. et al., "Investigation of thin film coating process parameter space for the Athena X-ray optics," Proceedings of SPIE 11822 (2021).

[17] Ferreira, D. D. M., Massahi, S., Svendsen, S., Henriksen, P. L., Christensen, F. E., Gellert, N., Vu, L. M., 'S Jegers, A., and Shortt, B., "X-ray mirror coatings for ATHENA: updated design, development status and performance," Proceedings of SPIE 11822 (2021).

[18] Svendsen, S., Enhancing the Athena telescope performance using X-ray mirror coatings, PhD thesis, Technical University of Denmark (2020).

[19] Landgraf, B. et al., "SPO mirror plate production and coating," Proceedings of SPIE 11822 (2021).

[20] Massahi, S., Christensen, F. E., Ferreira, D. D. M., et al., "Installation and commissioning of the Silicon Pore Optics coating facility for the ATHENA mission," Proceedings of SPIE 11119 (2019).

[21] Massahi, S., Industrialization of the mirror plate coatings for the ATHENA mission, PhD thesis, Technical University of Denmark (2019).

[22] Girou, D., Massahi, S., Ferreira, D., et al., "Plasma etching for the compatibility of thin film metallic coatings and direct bonding of silicon pore optics," Journal of Applied Physics 128(9) (2020).

[23] Henriksen, P. L. et al., "Design, performance, and utilization of the low-energy x-ray reflectometer," Journal of Astronomical Telescopes, Instruments, and Systems (2021). Submitted.

[24] Windt, D. L., "'IMD - Software for modeling the optical properties of multilayer films"," Computers in Physics 12(360) (1998). 